\title{
Multi Input Multi Output (MIMO) Control $2 \times 2$ at Vacuum Distillation Unit for LVGO, MVGO, and HVGO Production
}

\author{
Abdul Wahid, ${ }^{1, *}$, and Naufal Syafiq Maro ${ }^{1}$ \\ ${ }^{1}$ Chemical Engineering Department, Universitas Indonesia, Depok, Indonesia
}

\begin{abstract}
Currently, Indonesia is still experiencing a fuel deficit, so it is necessary to build a new oil refinery and a process optimization at an existing refinery. A vacuum distillation unit (VDU) is used to process the atmospheric residue products from crude distillation unit (CDU). A multivariable model predictive control (MMPC) is proposed to improve a control performance in VDU because of the interaction between variables in the unit. Therefore, it is necessary to find the variables that interact with each other. In this study only two variables are discussed. Set point (SP) and disturbance changes are used to test the control performance with integral of square error (ISE) as the indicator. The results are compared with the control performance of the PI controller and a single MPC. As a result, the feed flow rate and bottom-stage temperature are strongest interactions so that both are determined as controlled variables in MMPC. The control performance of MMPC is better than the PI controller and the single MPC with control performance improvement of $48 \%$ to the PI controller and $21 \%$ to MPC on for Feed Flow Rates, and $98 \%$ to the $\mathrm{PI}$ controller and $27 \%$ to MPC on Bottom Stage Temperature. While on disturbance changes the enhancement is $35 \%$ for the Bottom Stage Temperature.
\end{abstract}

\section{Introduction}

Vacuum Distillation Unit (VDU) is a secondary process unit in refinery. This unit is very important for fractionating atmospheric residue residue, bottom product of Crude Distillation Unit (CDU), which has boiling point more than $350^{\circ} \mathrm{C}$ [1]. Generally, VDU operates in $20-65 \mathrm{mmHg}$. As the pressure of the columns is reduced, the component's boiling point will be decreased as well. So that, it doesn't need high temperature to fractionate the atmospheric residue into lighter fraction.

VDU produces Light Vacuum Gas Oil (LVGO), Medium Vacuum Gas Oil (MVGO), and Heavy Vacuum Gas Oil (HVGO). These products can be processed further into gasoline and diesel product blending.

VDU has many variables that are very crucial to the stability of operation and product quality. Column temperature can stabilize the composition profile within the column. Temperature column gives indirect composition control [2]. As we know, column pressure affects boiling point of the component. Pressure fluctuations make control more difficult and reduce unit performance. In addition, pressure variations alter relative volatility and affects fractionation performance [3]. Feed flow rate and temperature will affect the vaporliquid contact and influence the product's composition [4]. In order to maintain the stability of operation and reject any disturbances, proper controllers are needed.
PI controllers are the most popularly used in the industry because the first controllers are used in the industry and are most easily understood compared to advanced process controllers [5-6]. However, PI controllers have not considered the problem of nonlinearities of process and inter-variable interaction. There are some types of advanced process controllers: model predictive control (MPC), multivariable MPC (MMPC) and multi MPC [7-9] are the example. PI is a controller that works by comparing the error value with the desired response and integrating it so that the difference becomes zero [10].

MPC predicts the future values of the process output using dynamic model and available measurement. The controller outputs are calculated so as to minimize the difference between the predicted process response and desired response [11]. MPC can improve control performance and stabilize unit operation by using optimization. Furthermore, operational costs can be minimized due to more economic process operation [12].

Wahid and Prasetio [13] has been researching singleinput single-output (SISO) MPC or single MPC applications on VDU. However, a SISO MPC has a weakness because it works like a PI controller that does not consider the inter-variable interactions that generally occur in a process. Therefore, in this research used multi-input mutl-output (MIMO) MPC or multivariable MPC (MMPC) to overcome the inter-variable interaction.

\footnotetext{
Corresponding author: wahid@che.ui.ac.id
} 


\section{Methodology}

\subsection{Simulation environment}

In this simulation, the feed that is going to be fractionated is atmospheric residue which flow rate is $118,021 \mathrm{bpd}$. The configuration of VDU simulation can be seen in Figure 1. In this configuration, feed and products (side streams such as LVGO, MVGO, and HVGO) flow rate are adjusted by flow rate controller. Feed temperature is controlled by controlling heater duty Top stage pressure is controlled by manipulating vapor flow rate. The condenser level is controlled by controlling overhead condensate flow rate. The bottom stage temperature is controlled by manipulating reboiler duty.

In the installation of the controller, the considerations are the control objective, the desired set-point (SP) value and the independent variable that will affect the SP when the dynamic behavior of the vacuum distillation unit system is performed. There are two types of controller which are used in this study, MPC and PI. Furthermore, these two types of controllers will be compared to see which controller provide the best performance.

\subsection{FOPDT models}

In this study, finding the control parameters that has interactions between them is important. Interaction can be described as the changing of one MV (manipulated variable) that affects other $\mathrm{CV}$ (controlled variable), other than its own. If it is determined the choice of interacting variables, then developed empirical model using first-order plus dead time (FOPDT) by carrying out a model testing in each $\mathrm{CV}$ to get process reaction curve (PRC).

The empirical model of FOPDT [14] is shown by equation (1)

$$
G_{p}(s)=\frac{K_{p} e^{-\theta s}}{\tau s+1}
$$

where, $\mathrm{K}_{\mathrm{P}}$ is process gain describing how far PV moves; $\tau$, time constant that describe how fast the PV respond; $\theta$ is dead time describing how much delay occurs before the PV first begins to move.

MMPC with inputs and outputs of $2 \times 2$ have four FOPDT models which can be expressed in matrix form of transfer functions as in the following equation:

$$
G(s)=\left[\begin{array}{ll}
G_{11}(s) & G_{12}(s) \\
G_{21}(s) & G_{22}(s)
\end{array}\right]
$$

\subsection{Controller tuning}

Based on FOPDT models, tune the parameters that determine optimization stages in MPC, ie., $T_{s}$ (sampling time), $\mathrm{P}$ (prediction horizon) and using identical model to compute M (control horizon). Shridhar \& Cooper [15] have developed a tuning method for MMPC, so this method is used in this study. Because this method is often less appropriate for some processes, then the fine tuning method is used [16-17].

\subsection{Controller performance}

The performance of the controller is tested by doing setpoint tracking and disturbance rejection. The disturbances are the elevation of feed flow rate by $10 \%$. Next is comparing the error value, ISE (integral square error), of the MPC and PI controllers to the set-point (SP) changes and also the disturbance to see which controller has more optimum performance. The smaller ISE values the better the performance of the controller. The equation of ISE can be seen as follow:

$$
I S E=\int_{0}^{\infty}(e)^{2} d t
$$

To know whether the obtained ISE is better, in this study the result are compared with previous research from Wahid and Prasetyo [12].

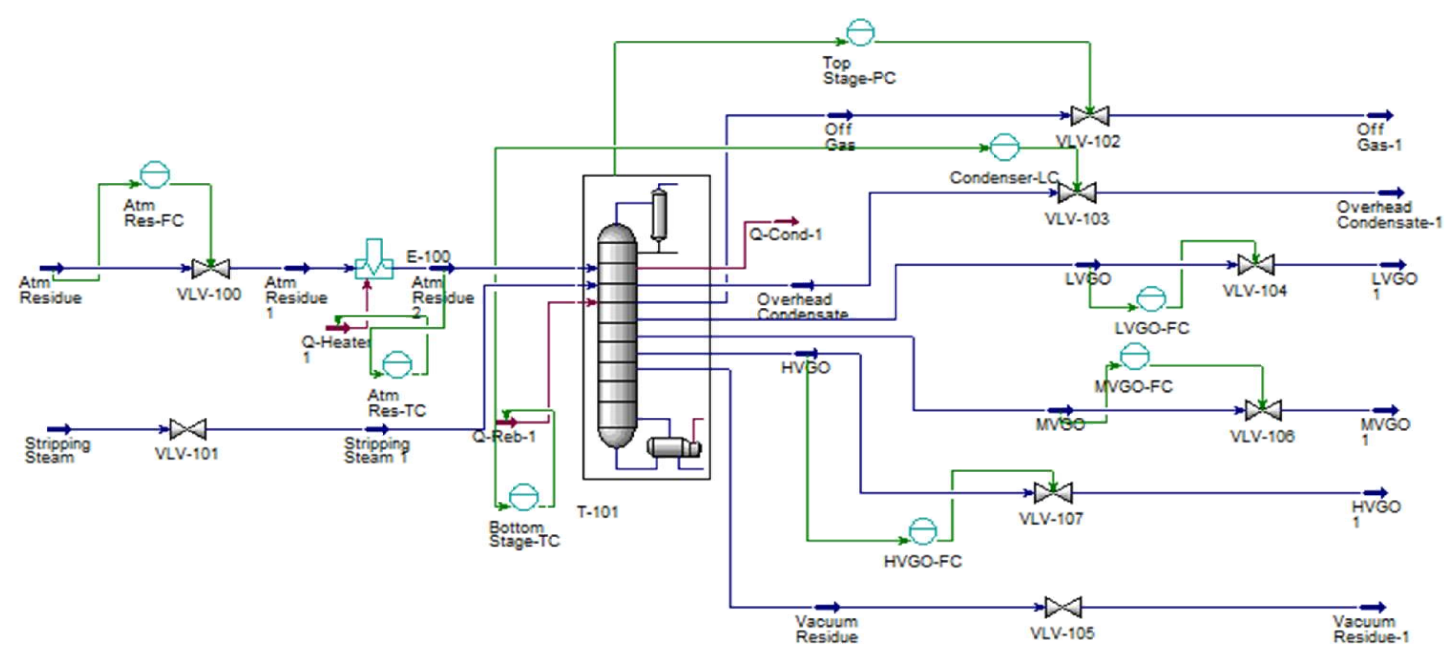

Fig 1. Configuration of VDU simulation 


\section{Results and discussion}

\subsection{The $2 \times 2$ models for MMPC}

After performing sensitivity testing of $\mathrm{CV}$ changes to MV changes, the strongest inter-variable interaction is between feed atmospheric residue flow rate (CV 1) and bottom stage temperature (CV 2) with the MVs of both are the feed flow rate (MV 1) and the heat duty of the reboiler (MV 2), respectively. Figure 3 shows the PRC of CV 1 and CV 2 caused by the MV 1 change, while Figure 3 shows the PRC of CV 1 and CV 2 caused by the MV 2 change. Based on the PRCs, the multivariable models in the form of FOPDT models are specified as shown in Table 1.

The MIMO model used in this study is expressed in the following equation:

$$
\left[\begin{array}{c}
F(s) \\
T_{B}(s)
\end{array}\right]=\left[\begin{array}{cc}
\frac{14.37 e^{-0.20 s}}{1.03 s+1} & \frac{3.81 e^{-0.01 s}}{0.99 s+1} \\
\frac{1.92 e^{-0.82 s}}{1.47 s+1} & \frac{5.04 e^{-0.94 s}}{1.09 s+1}
\end{array}\right]\left[\begin{array}{c}
F(s) \\
Q_{R}(s)
\end{array}\right]
$$

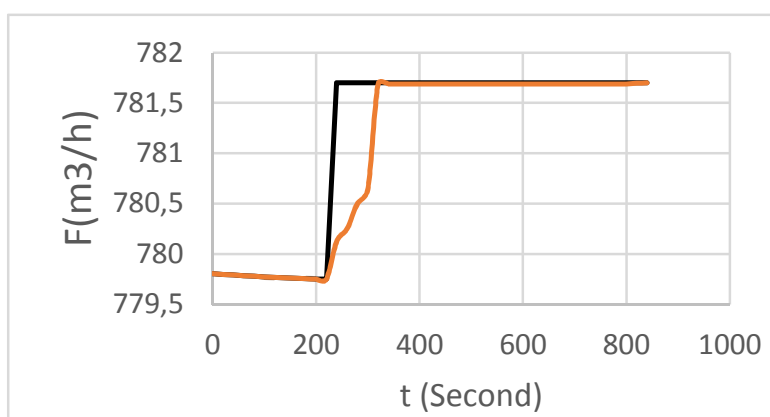

(a)
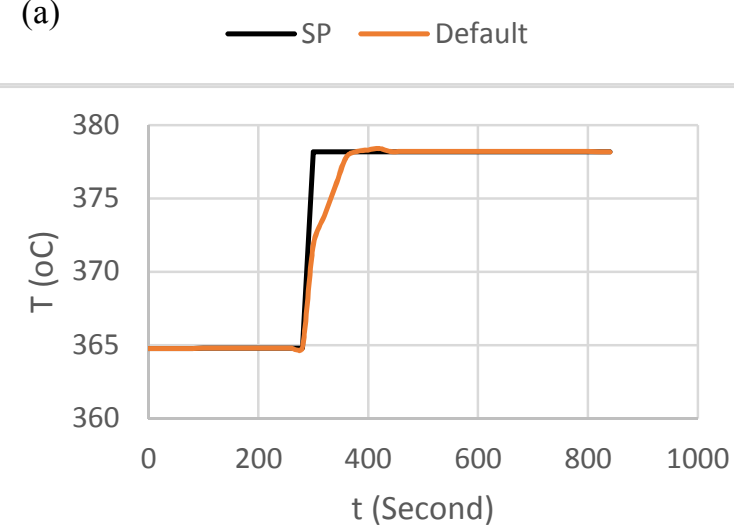

(b)

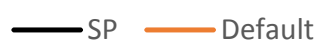

Fig 2. Response of (a) feed flow rate (CV 1) and (b) bottom stage temperature (CV 2) cause of feed flow rate (MV 1) change
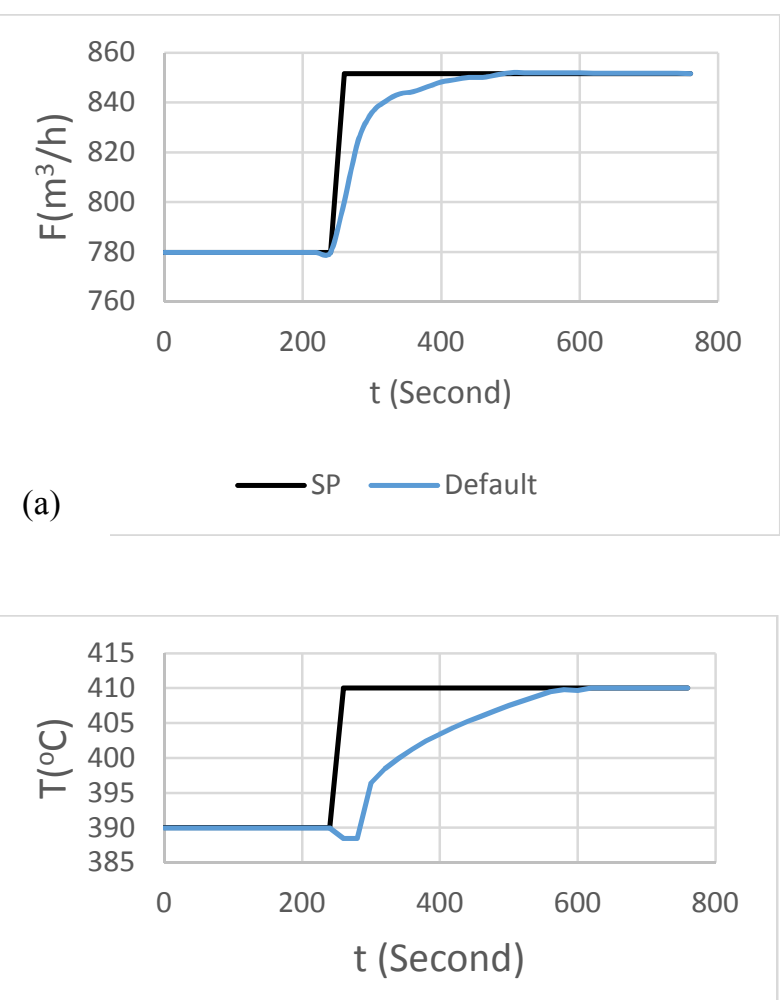

(b)

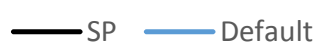

Fig 3. Response of (a) feed flow rate and (CV 1) (b) bottom stage pressure (CV 2) cause of feed flow rate (MV 2) change

Table 1. FOPDT models

\begin{tabular}{ccccc}
\hline & $\boldsymbol{G}_{\boldsymbol{p 1 1}}(\boldsymbol{s})$ & $\boldsymbol{G}_{\boldsymbol{p 1 2}}(\boldsymbol{s})$ & $\boldsymbol{G}_{\boldsymbol{p 2 1}}(\boldsymbol{s})$ & $\boldsymbol{G}_{\boldsymbol{p 2 2}}(\boldsymbol{s})$ \\
\hline $\boldsymbol{K}_{\boldsymbol{p}}$ & 14.37 & 3.81 & 1.92 & 5.04 \\
\hline $\boldsymbol{\tau}$ & 1.03 & 0.99 & 1.47 & 1.09 \\
\hline $\boldsymbol{\theta}$ & 0.20 & 0.01 & 0.82 & 0.94
\end{tabular}

Based on the multivariable model, MPC parameter tuning can be carried out using Shridhar-Cooper method [15], and the results are $T_{S}$ is $0.39, \mathrm{P}$ is 22 and $\mathrm{M}$ is 7 . Besides using the Shridhar-Cooper method, the tuning also carried out using the Fine Tuning method, this trial and error method is carried out in assumption that the result of Shridhar-Cooper method is not always suitable. The result from Fine Tuning method for $\mathrm{P}, \mathrm{M}$, and $T_{S}$ respectively are 10,3 , and 1 .

Table 2. Parameter tuning

\begin{tabular}{cccc}
\hline Tuning & \multicolumn{3}{c}{ Parameter } \\
\cline { 2 - 4 } Method & $\mathrm{P}$ & $\mathrm{M}$ & $\mathrm{T}$ \\
\hline $\begin{array}{c}\text { Shridhar- } \\
\text { Cooper }\end{array}$ & 22 & 7 & 0 \\
\hline Fine tuning & 10 & 3 & 1 \\
\hline
\end{tabular}

\footnotetext{
Corresponding author: wahid@che.ui.ac.id
} 


\subsection{SP tracking}

First performance test is carried out using Set Point tracking by increasing the Set Point of Feed Flow Rate from $781,8 \mathrm{~m}^{3} / \mathrm{h}$ to $1172.7 \mathrm{~m}^{3} / \mathrm{h}$. The initial Set Point is $781.8 \mathrm{~m}^{3} / \mathrm{h}$ because the process simulation reached stability at that point. The final SP is set at $1172.7 \mathrm{~m}^{3} / \mathrm{h}$ which is $50 \%$ more than the original Set Point, because in field condition disturbance on distillation column is really small or neglect-able $(<5 \%)$. For the Set Point of Bottom Stage Temperature, it is reduced from $390{ }^{\circ} \mathrm{C}$ to $354^{\circ} \mathrm{C}$ or $9.23 \%$.

The result are shown in Table 3. Fine tuning MMPC (MMPC-FT) shows better performance than Shridhar \& Cooper MMPC (MMPC-SC), single MPC and PI Controller. For Feed Flow Rate, the enhancement is $21.13 \%$, while Bottom Stage Temperature is $26.59 \%$.

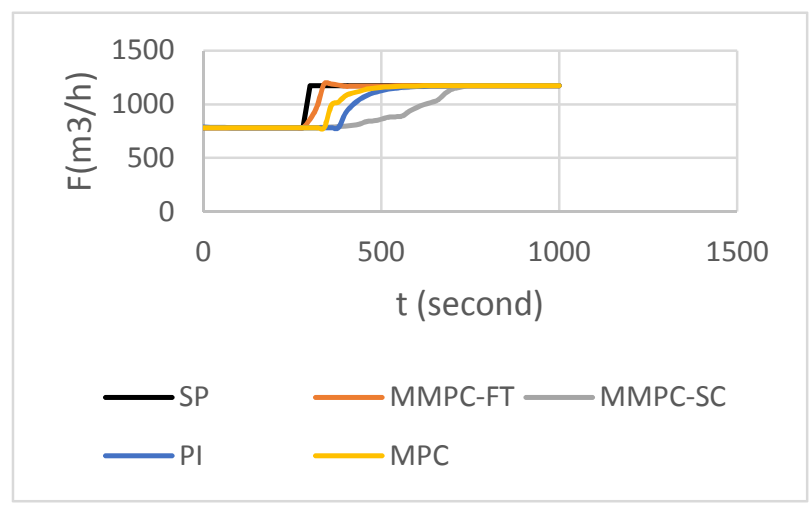

(a)

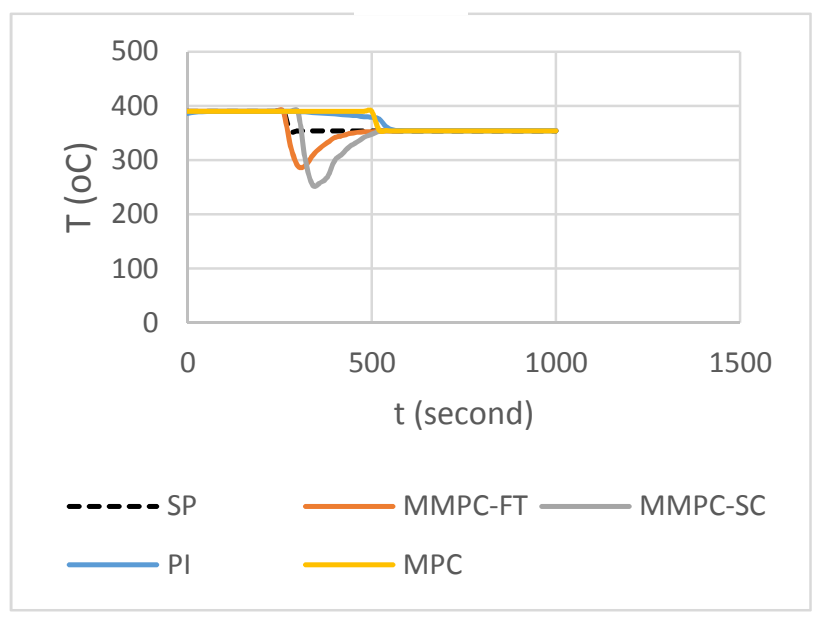

(b)

Fig 4. Response of (a) feed flow rate and (b) bottom stage temperature for a set point change.

Table 3. ISE comparison for SP tracking

$\begin{array}{cccc}\text { PI } & \text { MPC } & M M P C & \begin{array}{c}\text { Enhancement } \\ \text { FT }\end{array} \\ & & (\%)\end{array}$

\begin{tabular}{ccccc}
\hline Flow rate & 671 & 446 & 351.78 & 21.13 \\
\hline Temperature & 270 & 5.79 & 4.25 & 26.59 \\
\hline
\end{tabular}

\subsection{Disturbance rejection}

In field situation disturbance rarely occurred, but in order to test the performance of the controller in this study we can test it by increasing the feed flow rate by $10 \%, 25 \%$, and $50 \%$ and see the response given by the bottom stage temperature.

Figure 5 shows the response of bottom stage temperature for a change of $10 \%, 25 \%$, and $50 \%$ of feed flow rate. Because the test is carried out with the changing of feed flow rate, so the performance is only measured on bottom stage temperature. Table 4 shows the performance of the controller. Disturbance rejection test also shows that MMPC-FT is the better controller with enhancement of $35 \%$.

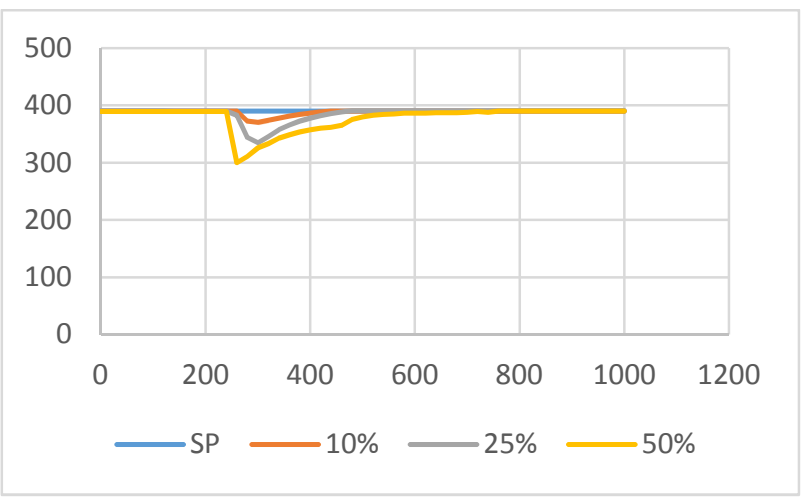

Fig 5. Response of bottom stage temperature for a change of $10 \%, 25 \%$, and $50 \%$ of feed flow rate.

The result are shown in Table 4 .

Table 4. ISE comparison for disturbance rejection

\begin{tabular}{cccc}
\hline & MPC & $\begin{array}{c}\text { MMPC } \\
\boldsymbol{F T}\end{array}$ & $\begin{array}{c}\text { Enhanc } \\
\text { ement } \\
(\mathbf{\%})\end{array}$ \\
\hline Temperature & 6 & 3.899 & 35 \\
\hline
\end{tabular}

\section{Conclusion}

As a result, the feed flow rate and bottom-stage temperature are strongest interactions so that both are determined as controlled variables in MMPC. The models can represent the process to control using multivariable model predictive control with tuning parameters of MPC are $T_{S}$ is $1, \mathrm{P}$ is 10 and $\mathrm{M}$ is 3 . Reviewed from the ISE value of SP Tracking, MMPC control is the better controller compared to PI and MPC of previous study with control performance improvement of $48 \%$ to the PI controller and $21 \%$ to MPC for Feed Flow Rate, and $98 \%$ to the PI controller and $27 \%$ to MPC for Bottom Stage Temperature. While on disturbance change the enhancement is $35 \%$ on Bottom Stage Temperature. 
We express our gratitude to the Universitas Indonesia which has funded this research through the scheme of Hibah Publikasi Internasional Terindeks untuk Tugas Akhir Mahasiswa (PITTA) No.2358/UN2.R3.1/HKP.05.00/2018.

\section{References}

1. Chilingarian G V and Yen T F Asphaltenes and Asphalts, 1, Amsterdam: Elsevier (1994)

2. Skogestad S, The dos and don'ts of distillation column control Chem. Eng. Res. Des. 85(A1) 1323(2007)

3. Sloley A W 2001 Effectively Control Column Pressure.Texas: The Distillation Group Inc. (2001)

4. Akpa J G and Umuze O D, Simulation of a multicomponent crude distillation column. Am. J. Sci. Ind. Res. 4(4) 366-77. (2013)

5. Astr"om, K.J., H"agglund, T., Hang, C.C., and Ho, W.K. Automatic tuning and adaptation for PID controllers - a survey. Cont. Eng. Practice, 1, 699714. Kano M and Ogawa M 2010 The state of the art in chemichal process control in Japan: Good practice and questionnaire survey $J$. Process Contr. 20 969-82. (1993).

6. Kano $M$ and Ogawa $M$, The state of the art in chemichal process control in Japan: Good practice and questionnaire survey J. Process Contr. 20 96982. (2010)

7. A. Wahid and A. Ahmad, Min-max controller output configuration to improve multi-model predictive control when dealing with disturbance rejection. International Journal of Technology. 6 (3): 504-515(2015).

8. A. Wahid and A. Ahmad, Improved multi-model predictive control to reject very large disturbances on a distillation column. International Journal of Technology. 6: 962-971(2016).

9. Ahmad A. and Wahid A Application of model predictive control (MPC) tuning strategy in multivariable control of distillation column. Reaktor 11(2) 66-70. (2007)

10. Marlin T E, Process Control: Designing Processes and Control System for Dynamic Performance. 2nd Edition. New York: Mc Graw-Hill, (2000)
11. Camacho, E. F., \& Bordons, C. Model Predictive Control. Sevilla: Springer (2007).

12. Himmelblau D M, Edgar T F and Lasdon L S Optimization of Chemical Processes, Second Edition. New York: McGraw-Hill (2001)

13. A Wahid and A P Prasetyo. A Comparative study between MPC and PI controller to control vacuum distillation unit for producing LVGO, MVGO, and HVGO. IOP Conf. Series: Materials Science and Engineering 334, 012020 (2018)

14. Smith C A and Corripio A B Principles and Practice of Automatic Process Control. New York: John Wiley \& Sons Inc. (1997)

15. Shridhar, R., \& Cooper, D. J. A Tuning Startegy for Unconstrained Multivariable Model Predictive Control. Control Engineering Practice, 37, 4003 4016. (1998).

16. A Wahid and I G E P Putra. Multivariable Model Predictive Control Design of Reactive Distillation Column for Dimethyl Ether Production. IOP Conf. Series: Materials Science and Engineering 334, 012018(2018).

17. A Wahid and F F Adicandra. Optimization Control of LNG Regasification Plant using Model Predictive Control. IOP Conf. Series: Materials Science and Engineering 334, 012022 (2018) 